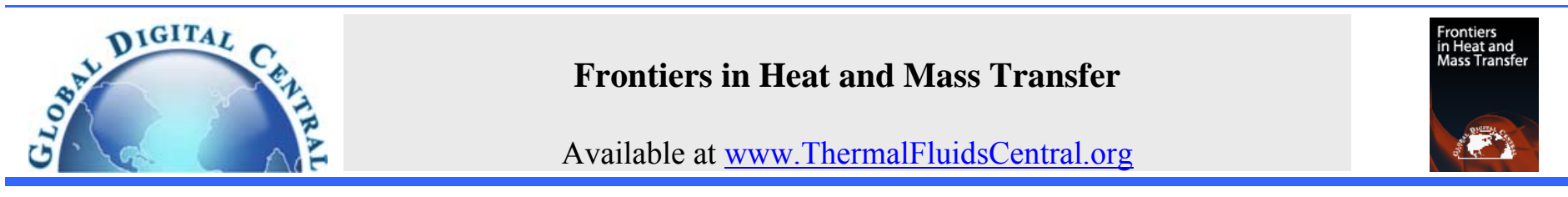

\title{
EFFECT OF DIFFERENT SHAPES ON CHARACTERISTICS OF CONJUGATE HEAT TRANSFER OF MICRO CHANNEL HEAT SINK
}

\author{
Ankit Kanor, R Manimaran* \\ School of Mechanical and Building Science, VIT University, Chennai Campus, Tamil Nadu, 600127, India
}

\begin{abstract}
One of the effective liquid cooling techniques for microelectronic devices is attaching micro channel heat sink to the inactive side of chip. A micro channel heat sink is a device that decreases temperature by flowing coolant through micro channels. The present study focuses on the conjugate heat transfer analyses for different cross-sections (trapezoidal, hexagonal, octagonal and circular).After present study is validated with the published result in the literature, the comparative study of parallel and counter flow configuration is performed. Different geometries are modeled using CATIA V5 software and simulated in ANSYS Fluent R14. From these CFD simulations, preferred configuration of parallel-flow or counter-flow is chosen based on maximum possible heat transfer for effective cooling. The focus on the analyses is to improve the heat transfer rate by either decreasing the chip wall (bottom wall) temperature or the decrease in overall thermal resistance.
\end{abstract}

Keywords: Geometrical shape, Micro channel Heat Sink, Computational Fluid Dynamics (CFD), Bottom wall temperature, Thermal resistance.

\section{INTRODUCTION}

To minimize the time between submission and publication, Microelectronics devices are very common in today's day to day life; their performance has a unique importance as they are found in most of the household appliances. The common problem that affects the performance of these devices is heat generation. It is important to cool them reliably and efficiently and promote longevity. For cooling purpose, a fan can be used. However, the fan can dissipate only a little magnitude of heat. Hence a micro-channel heat sink is preferred over fan for an effective cooling purpose. Here in this study a micro-channel heat sink is used, which has channel dimensions ranging from $10^{-6} \mathrm{~m}$ to $10^{-3} \mathrm{~m}$. Many researchers have tried to achieve the objective of cooling the devices with micro-channel in different ways by varying different parameters. The heat transfer coefficient is a prime factor to reduce thermal resistance and increase heat transfer. High aspect ratio increases surface area to an extent that reduces the thermal resistance further. Each geometrical parameter has a significant role in the performance of micro-channel heat sink. Leela Vinodhal and Rajan (2014) presented design of inlet-outlet plenum of micro channel has effect on uniformity of flow through channel which increases the rate of heat transfer and the Nusselt number depending on the hydrodynamic flow conditions.

Leng et al. (2015) presented that the parameters affecting bottom wall temperature and thermal resistance of micro channel heat sink are Number of channel, width of channel, height of channel, inlet velocity. The circular cross section gives the uniform flow distribution among all the channels and it can be manufactured by using Low Temperature Cofired Ceramic (LTCC) technology. Brinda et al. (2012) presented ladder shape heat sink as the effective one. The effect of geometrical parameters and their shape on conjugate heat transfer was further extended by comparison of the rectangle, trapezoidal and triangular geometrical section. Gunnasegaran et al. (2010) found that effective temperature distribution and rate of heat transfer is observed in rectangular section which has small hydraulic diameter.

The performance of heat sink can also be enhanced by stacking the channel on one another, as more fluid flow area will enhance the cooling rate of micro channel. The counter flow of fluid among the channels gives better uniformity in temperature. In the present study, the three new geometries are introduced viz. Hexagonal, circular and octahedral shapes of the channels. Theoretical comparison for heat transfer coefficient and thermal resistance are performed. All the geometries are analyzed for similar flow rates in the trapezoidal geometry case whose experimental work results are available from the literature. All the design calculations are carried out for different geometries and modeled in CATIA V5. All the four geometric designs are analyzed in the CFD software, ANSYS FLUENT R14 for conduction-convection heat transfer characteristics. The CFD results were compared with the experimental results from result of Wei et al. (2007). CFD simulations are performed for parallel and counter flow conditions under constant heat flux conditions. The behavior of the flow and heat transfer characteristics is examined for the geometries considered in the present study.

The design specification for trapezium geometry was taken from the reference. The flow of water from the trapezoidal section of micro channel was presented by Qu et al. (2000). The other geometries are maintained at same cross sectional area and flow rate but different inlet aspect ratio and hydraulic diameter. The flow rate is varied as per the flow conditions of trapezoidal geometry and the results are analyzed. The geometries are chosen on the basis of three parameters like aspect ratio, hydraulic diameter, and surface area. High aspect ratio, low hydraulic diameter, and high surface area reduce the thermal resistance and increase rate of heat transfer. All these parameters are interrelated to each other and their variation has effect on coefficient of heat transfer for different geometries. Thus the geometry having optimum values of this parameter shows the effective result. The value of these parameters is shown in the Table 1. 
Table 1 - Different parameters for various geometries.

\begin{tabular}{|l|c|c|c|}
\hline Geometries & Aspect ratio & $\begin{array}{l}\text { Hydraulic } \\
\text { diameter }(\mathrm{mm})\end{array}$ & $\begin{array}{l}\text { Surface area } \\
\left(\mathrm{mm}^{2}\right)\end{array}$ \\
\hline Trapezoidal & 0.1937 & 0.389 & $\mathbf{6 . 9}$ \\
\hline Octahedral & 0.877 & $\mathbf{0 . 0 1 1 5 9}$ & 5.368 \\
\hline Hexagonal & $\mathbf{1 . 1 5 6}$ & 0.0135 & 4.68 \\
\hline Circular & 1 & 0.141 & 4.43 \\
\hline
\end{tabular}

As shown in the Table 1, the trapezoidal geometry has high heat transfer surface area, octahedral geometry has least hydraulic diameter, and hexagonal geometry has high aspect ratio. All these parameters increases coefficient of heat transfer and reduces thermal resistance. Thus coefficient of heat transfer and thermal resistance are taken as the objective function in this study.

\section{GEOMETRIC CONFIGURATION}

In this study four geometries are chosen for comparison with silicon as material and deionized water as coolant. The properties of both the materials are given in Table 2.

Table 2 - Material Properties

\begin{tabular}{|l|l|l|l|l|}
\hline Materials & $\begin{array}{l}\text { Density } \\
\left(\mathrm{kg} / \mathrm{m}^{3}\right)\end{array}$ & $\begin{array}{l}\text { Specific } \\
\text { heat } \\
(\mathrm{KJ} / \mathrm{kg} \mathrm{K})\end{array}$ & $\begin{array}{l}\text { Thermal } \\
\text { conductivity } \\
(\mathrm{W} / \mathrm{m} \mathrm{K})\end{array}$ & $\begin{array}{l}\text { Dynamic } \\
\text { viscosity } \\
(\mathrm{kg} / \mathrm{m} \mathrm{s})\end{array}$ \\
\hline Water & 997 & 4179 & 0.613 & 0.000855 \\
\hline Silicon & 2329 & 710 & 148 & - \\
\hline
\end{tabular}

The geometries are modeled by maintaining the cross section area and flow rate same for all the channels. The geometrical parameters are per given in Table 3. All geometries are modeled in CATIA V5 as shown in figure 1 to figure 4 .

$$
\mathrm{Ac}_{1}=0.01562 \mathrm{~mm}^{2}, \mathrm{Ac}_{2}=0.013851 \mathrm{~mm}^{2}
$$

Width of channels $=0.02 \mathrm{~mm}$, Length of channels $=0.96 \mathrm{~mm}$

Table 3 - Design parameters of geometries in mm

\begin{tabular}{|l|l|l|l|l|}
\hline $\begin{array}{l}\text { Paramete } \\
\text { rs }\end{array}$ & Trapezium & Octahedral & Hexagonal & Circular \\
\hline $\mathrm{H}_{\mathrm{ch} 1}$ & 0.284 & 0.171 & 0.134 & 0.141 \\
\hline $\mathrm{H}_{\mathrm{ch} 2}$ & 0.243 & 0.152 & 0.126 & 0.133 \\
\hline $\mathrm{W}_{\mathrm{ch} 1}$ & $\begin{array}{l}\mathrm{W}_{\mathrm{ct} 1}=0.056 \\
\mathrm{~W}_{\mathrm{ct} 2}=0.054\end{array}$ & 0.150 & 0.155 & 0.142 \\
\hline $\mathrm{W}_{\mathrm{ch} 2}$ & $\begin{array}{l}\mathrm{W}_{\mathrm{ct} 3}=0.061 \\
\mathrm{~W}_{\mathrm{ct} 4}=0.053\end{array}$ & 0.153 & 0.146 & 0.132 \\
\hline $\begin{array}{l}\Delta \mathrm{p} \\
(\mathrm{Mpa})\end{array}$ & 0.247 & 0.124 & 0.138 & 0.141 \\
\hline $\begin{array}{l}\Delta \mathrm{p} \\
(\mathrm{Mpa})\end{array}$ & 0.257 & 0.139 & 0.157 & 0.159 \\
\hline
\end{tabular}

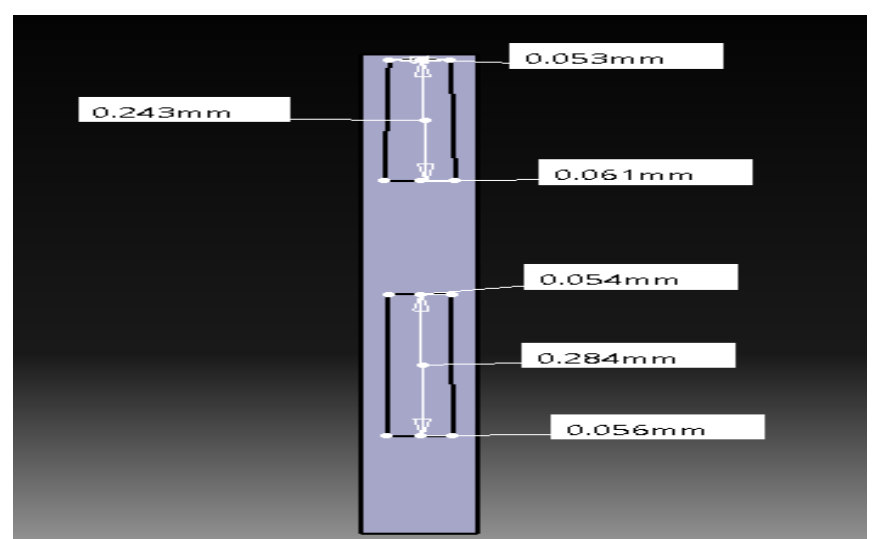

Fig 1 - Trapezoidal geometry

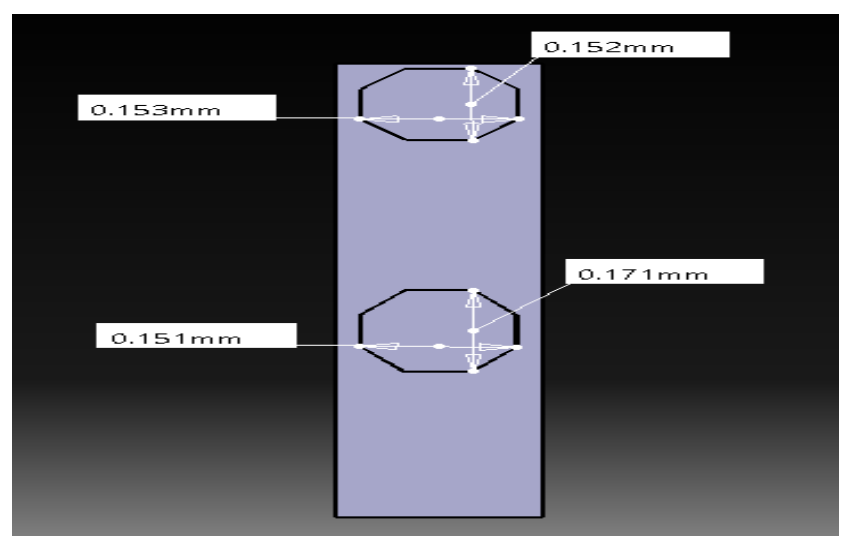

Fig. 2 Octahedral geometry

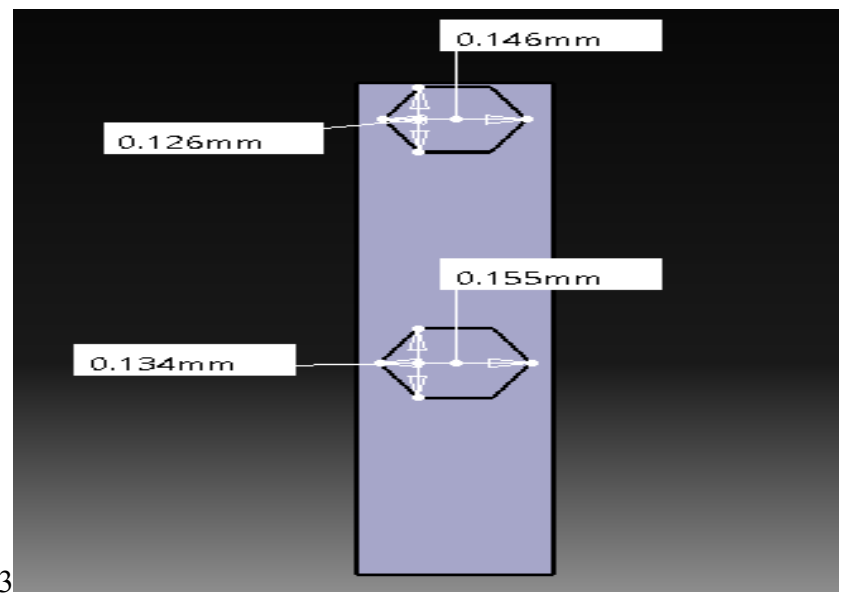

Fig. 3 Hexagonal geometry

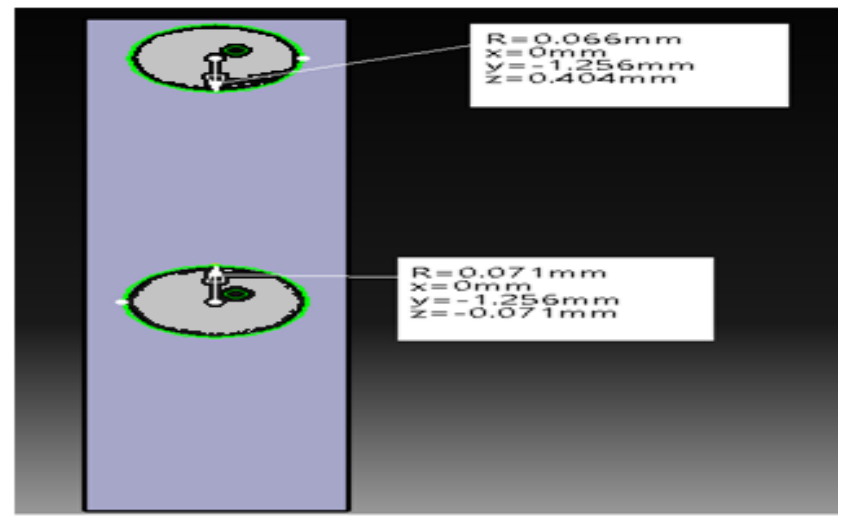

Fig. 4 Circular geometry 


\section{THEORETICAL CALCULATION}

The Theoretical evaluation of coefficient of heat transfer and thermal resistance is carried out. The geometry with low thermal resistance and high coefficient of heat transfer will have high heat transfer. For steady flow, laminar, constant heat flux,

$\mathrm{Nu}=$ Nusselt number $=4.36$

$\mathrm{D}_{\mathrm{h}}=$ hydraulic diameter $=\left(4 \mathrm{~A}_{\mathrm{s}}\right) / \mathrm{p}_{\mathrm{wet}}$

$\operatorname{Re}=\left(\rho \vee D_{h}\right) / \mu$

$\mathrm{Nu}=\left(\mathrm{h} \mathrm{D}_{\mathrm{h}}\right) / \mathrm{K}_{\mathrm{f}}$

$\mathrm{R}_{\mathrm{th}}=\left(\mathrm{L} / \mathrm{K}_{\mathrm{f}}\right)+(1 / \mathrm{h})$

$\mathrm{U}=$ overall thermal resistance $=\left(1 / \mathrm{R}_{\mathrm{th}}\right)$

Table 4 - Coefficient of Heat transfer $(\mathrm{h})$

\begin{tabular}{|l|l|l|}
\hline Geometry & \multicolumn{1}{|c|}{$\begin{array}{c}\mathrm{h}_{1} \\
\left(\mathrm{~W} / \mathrm{m}^{2} \mathrm{~K}\right)\end{array}$} & $\begin{array}{c}\mathrm{h}_{2} \\
\left(\mathrm{~W} / \mathrm{m}^{2} \mathrm{~K}\right)\end{array}$ \\
\hline Trapezoidal & $28,987.85$ & $28,956.45$ \\
\hline Octahedral & $23,040.34$ & $24,385.76$ \\
\hline Hexagonal & $19,945.37$ & $21,211.74$ \\
\hline Circular & $18,955.17$ & $20,247.5$ \\
\hline
\end{tabular}

Table 5 - Thermal resistance and overall thermal resistance

\begin{tabular}{|l|l|l|}
\hline Geometry & \multicolumn{1}{|c|}{$\begin{array}{l}\mathrm{R}_{\text {th }} \\
\left(\mathrm{K} /\left(\mathrm{w} / \mathrm{m}^{2}\right)\right)\end{array}$} & $\mathrm{U}$ \\
\hline Trapezoidal & $3.58 * 10^{-5}$ & $27,932.96$ \\
\hline Octahedral & $4.549 * 10^{-5}$ & $21,982.55$ \\
\hline Hexagonal & $5.247 * 10^{-5}$ & $19,056.77$ \\
\hline Circular & $5.5046 * 10^{-5}$ & $18,166.43$ \\
\hline
\end{tabular}

The results of theoretical evaluation for coefficient of heat transfer and thermal resistance are shown in Table 4, 5. The trapezoidal geometry and octahedral geometry have low thermal resistance and high coefficient of heat transfer compare to other geometries. Thus comparatively trapezoidal and octahedral geometry will exhibit high rate of heat transfer than other geometries. The circular geometry has least coefficient of heat transfer and high thermal resistance, thus it will exhibit low rate of heat transfer.

\section{COMPUTATIONAL ANALYSES}

Table 6 - Computational flow conditions

\begin{tabular}{|l|l|l|l|l|l|}
\hline $\begin{array}{l}\text { Heat flux } \\
\left(\mathrm{W} / \mathrm{m}^{2}\right)\end{array}$ & $\begin{array}{l}\text { Flow Rate } \\
(\mathrm{m} 1 / \mathrm{min})\end{array}$ & $\begin{array}{l}\mathrm{T}_{\mathrm{f} 1} \\
(\mathrm{~K})\end{array}$ & $\begin{array}{l}\mathrm{T}_{\mathrm{f} 2} \\
(\mathrm{~K})\end{array}$ & $\begin{array}{l}\mathrm{V}_{1} \\
(\mathrm{~m} / \mathrm{s})\end{array}$ & $\begin{array}{l}\mathrm{V}_{2} \\
(\mathrm{~m} / \mathrm{s})\end{array}$ \\
\hline 710000 & 83 & 294.59 & 294.26 & 0.8842 & 1.0254 \\
\hline 710000 & 116 & 294.59 & 294.26 & 1.237 & 1.39 \\
\hline 710000 & 147 & 294.59 & 294.26 & 1.56 & 1.77 \\
\hline 710000 & 177 & 294.59 & 294.26 & 1.88 & 2.13 \\
\hline
\end{tabular}

A commercial software ANSYS FLUENT (version 14.0) is used for the performance analysis of the geometries. The geometries are imported in ANSYS where fluid and solid part are defined. Then by the grid independency test the high quality mesh size is obtained. Then all the boundary conditions and materials with material properties are assigned as per Table 6 and 2 respectively. The results are obtained for different flow rates for each geometry. The fluid flow is examine for two type of flow conditions parallel flow and counter flow, under constant heat flux condition over the bottom wall. The bottom wall of heat sink is the surface where the Integrated Circuit of the electronic device is placed. It transfers heat to bottom wall of micro channel that is cooled by water.

\section{RESULTS AND DISCUSSION}

The analysis of each geometrical configuration for different flow rate is performed. It was found that the peak temperature is obtained in parallel flow condition for all geometries and the uniformity in temperature is obtained in counter flow conditions. On the basis of the computational result obtained by the analysis the variation in the bottom wall temperature is observed. The bottom wall temperature increases up to certain maximum temperature that is obtained in middle of the channel and decreases after then. This behavior is shown in the figure 11 to 14 . It is observed from the graph that for the lower flow rate octahedral geometry and for high flow rate trapezoidal geometry shows result closer to experimental result. These results are within $2 \%$ variation from the experimental result done by Wei et al. (2007).

\subsection{Parallel flow conditions}

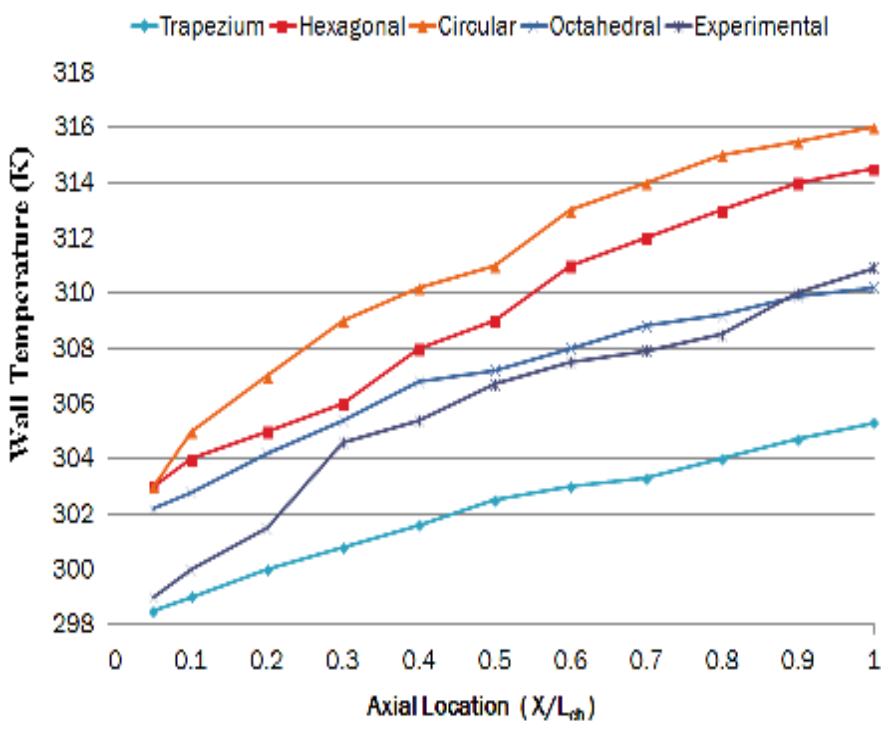

Fig. 5 For flow rate $83 \mathrm{ml} / \mathrm{min}$

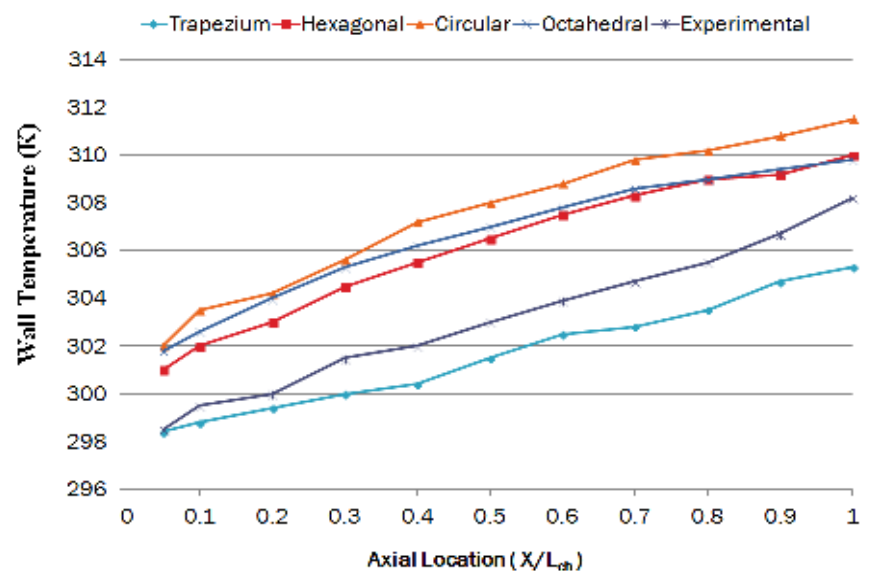

Fig. 6 For flow rate $116 \mathrm{ml} / \mathrm{min}$

The parallel flow condition shows the linear increase in bottom wall temperature. The peak temperature is obtained in the parallel flow condition as in the figure $7-10$. Thus parallel flow is not much effective in decreasing bottom wall temperature. 


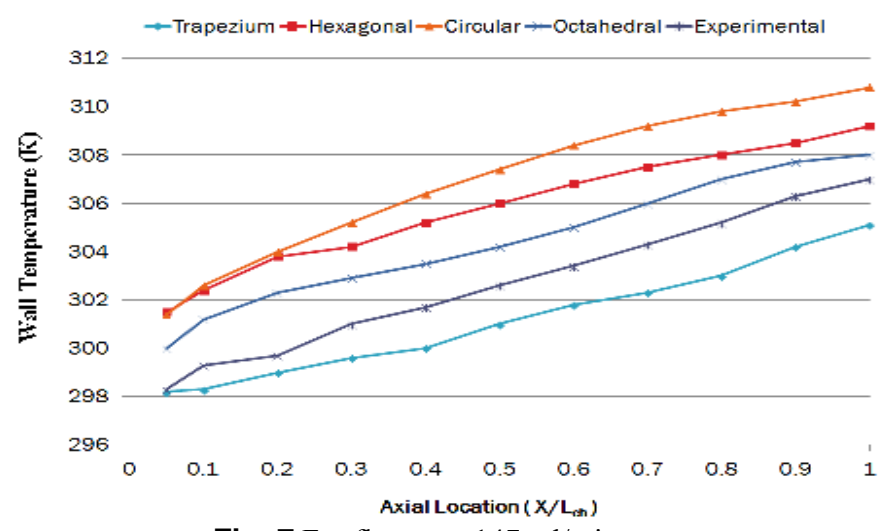

Fig. 7 For flow rate $147 \mathrm{ml} / \mathrm{min}$

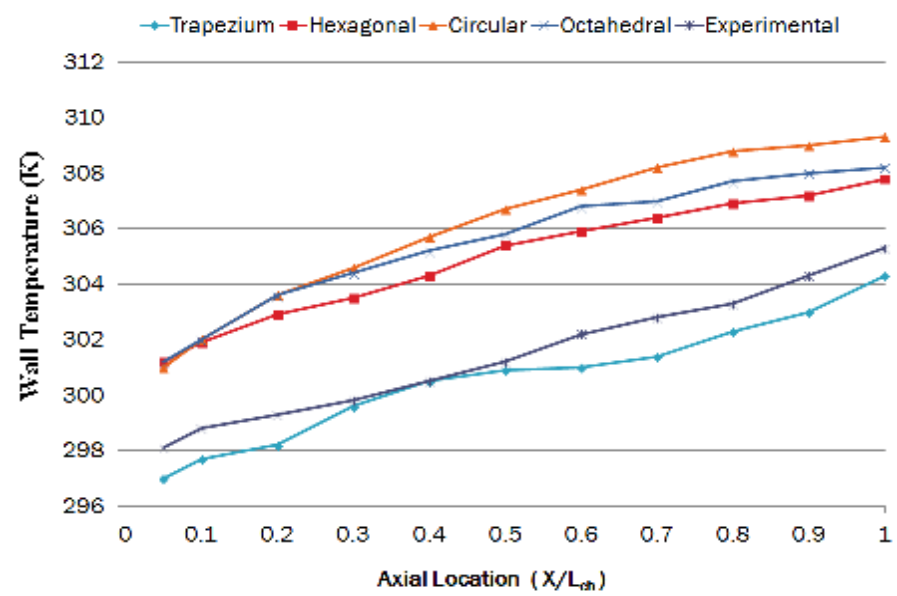

Fig. 8 For flow rate $177 \mathrm{ml} / \mathrm{min}$

\subsection{Counter flow conditions}

The counter flow results have shown in the figure 9 to 12 . The temperature variations of bottom wall under same flow rate in both channels for all geometries. The direction of flow varies, which in turn decreases the bottom wall temperature to large extent. The counter flow condition decreases the bottom wall temperature. The computational results for all geometries have maximum variation of less than $2 \%$ from the experimental results as shown in table 1.7. Thus all the geometries are effective, but octahedral geometry shows very less maximum variation as compared to other geometries for lower flow rate whereas for high flow rate the trapezoidal geometry is better.

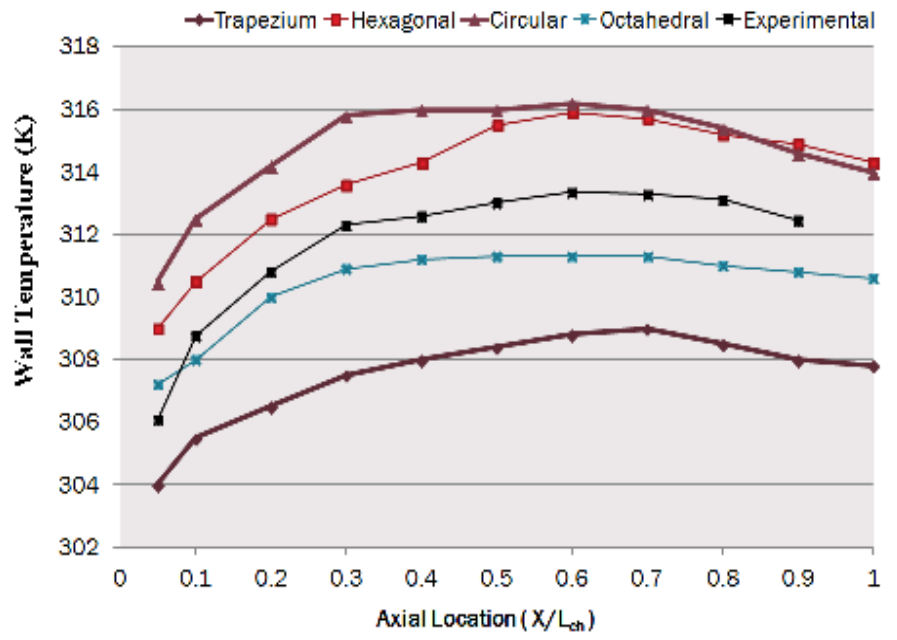

Fig. 9 For Flow rate $83 \mathrm{ml} / \mathrm{min}$ $\rightarrow$ Trapezium $\rightarrow$-Hexagonal $\rightarrow$-Circular $\rightarrow-$ Octahedral $*$-Experimental

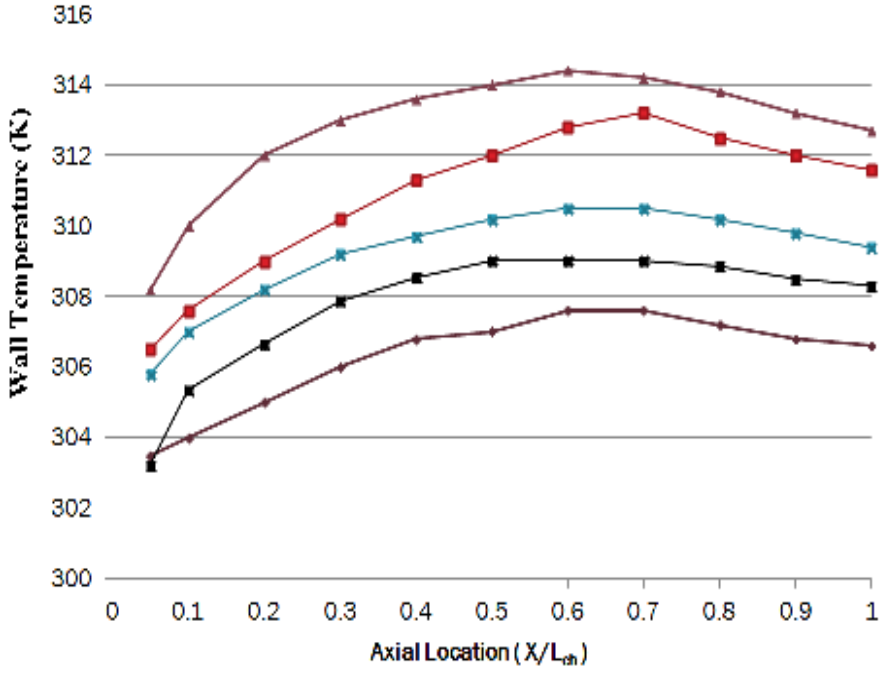

Fig. 10 For Flow rate $116 \mathrm{ml} / \mathrm{min}$

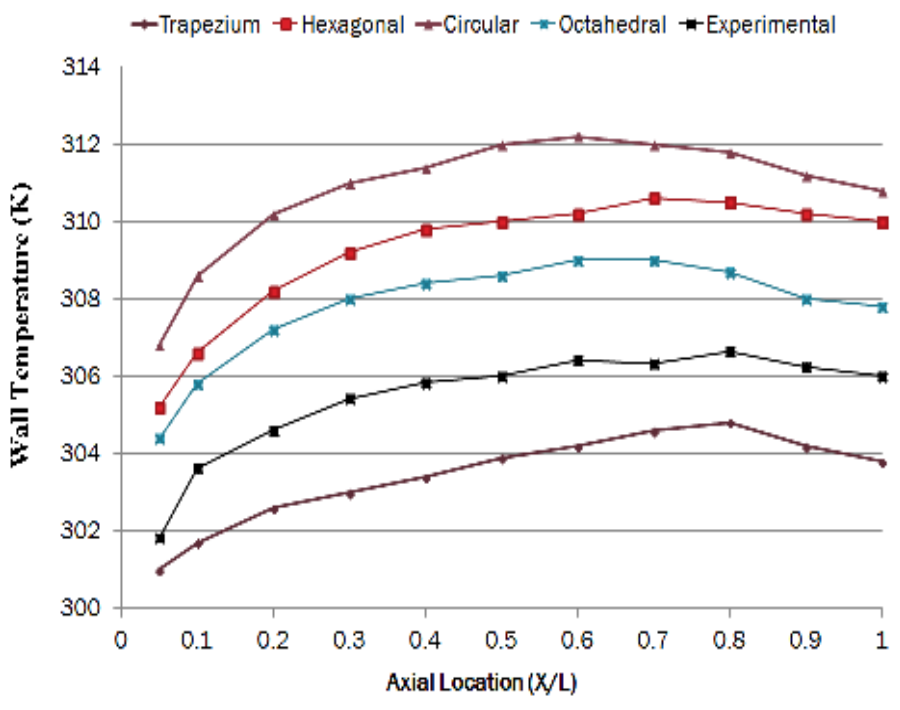

Fig. 11 For flow rate $147 \mathrm{ml} / \mathrm{min}$

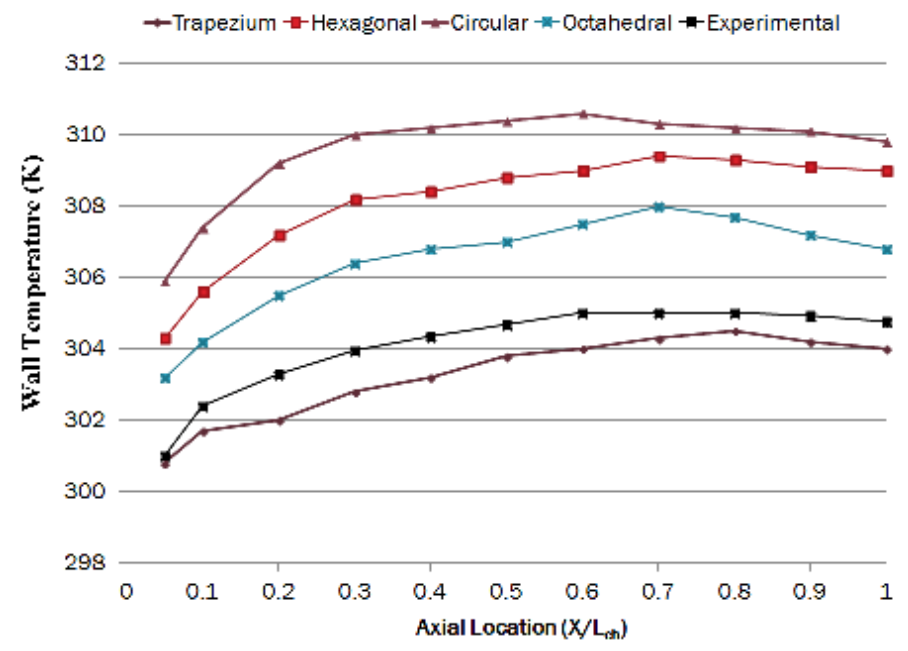

Fig. 12 For flow rate $177 \mathrm{ml} / \mathrm{min}$ 
Table 7 - Maximum variation of computational result from experimental result of trapezoidal geometry

\begin{tabular}{|l|l|l|l|l|}
\hline Flow rate & Trapezium & Octahedral & Hexagonal & Circular \\
\hline $\begin{array}{l}83 \\
\mathrm{ml} / \mathrm{min}\end{array}$ & $1.54 \%$ & $0.97 \%$ & $0.9443 \%$ & $1.326 \%$ \\
\hline $\begin{array}{l}116 \\
\mathrm{ml} / \mathrm{min}\end{array}$ & $0.655 \%$ & $0.844 \%$ & $1.204 \%$ & $1.71 \%$ \\
\hline $\begin{array}{l}147 \\
\mathrm{ml} / \mathrm{min}\end{array}$ & $0.79 \%$ & $0.865 \%$ & $1.84 \%$ & $1.92 \%$ \\
\hline $\begin{array}{l}177 \\
\mathrm{ml} / \mathrm{min}\end{array}$ & $0.43 \%$ & $0.97 \%$ & $1.86 \%$ & $1.84 \%$ \\
\hline
\end{tabular}

\section{CONCLUSION}

The maximum variation for all geometries from experimental result is found to be less than $2 \%$ as shown in table 1.7 . Thus the computational results stay in well agreement with the theoretical results. For lower flow rate octahedral and hexagonal geometry has least variation from experimental result. The maximum wall temperature for octahedral geometry is less than that for hexagonal geometry. Thus the octahedral geometry is preferred over hexagonal geometry for the low flow rates. For the higher flow rate the trapezoidal and octahedral geometry shows small variation from experimental result as compared to hexagonal and circular geometry. Thus for high flow rate, trapezoidal and octahedral geometry is better. The maximum wall temperature for trapezoidal geometry is less than that for octahedral geometry. Hence trapezoidal geometry is considered better for higher flow rate. The micro channel heat sink is more effective for low flow rate, as it requires less pumping power. Thus octahedral geometry is preferred.

The Octahedral geometry is better than trapezoidal geometry for lower flow rate as it has very less hydraulic diameter, very high Aspect Ratio and slightly less surface area as compare to trapezoidal geometry. At high flow rate the turbulence effect comes into play. The Octahedral geometry has more corner areas and has more turbulence effect than trapezium geometry. Thus at low flow rate Octahedral geometry and at high flow rate Trapezium geometry is preferred.

\section{FUTURE SCOPE}

The geometries can be examined for the turbulent flow condition as the micro channel contains some corner area where the flow can be turbulent. The geometries can be analyzed and tested for non uniform heating condition.

\section{ACKNOWLEDGEMENT}

The experimental work done by Xiaojin Wei et al. is acknowledged. The discussions with Dr.Umashankar during the course of some part of the work are acknowledged.

\section{NOMENCLATURE}

HCh1 Bottom channel height (mm)

$\mathrm{H}_{\mathrm{Ch} 2} \quad$ Top channel height $(\mathrm{mm})$

Wh1 Width of Bottom channel (mm)

$\mathrm{W}_{\mathrm{Ch} 2} \quad$ Width of Top channel $(\mathrm{mm})$

$\Delta \mathrm{p} \quad$ Change in pressure $\left(\mathrm{N} / \mathrm{mm}^{2}\right)$

$\mathrm{W}_{\mathrm{ctl}} \quad$ Bottom width of bottom channel of trapezium $(\mathrm{mm})$

$\mathrm{W}_{\mathrm{ct} 2} \quad$ Top width of bottom channel of trapezium $(\mathrm{mm})$
$\mathrm{W}_{\mathrm{ct3}} \quad$ Bottom width of top channel of trapezium $(\mathrm{mm})$

$\mathrm{W}_{\mathrm{ct} 4} \quad$ Top width of top channel of trapezium $(\mathrm{mm})$

$\mathrm{R}_{\text {th }} \quad$ Thermal Resistance $(\mathrm{mm})$

$\mathrm{U} \quad$ Overall thermal resistance

$\mathrm{P}_{\text {wet }} \quad$ Wetted perimeter $(\mathrm{mm})$

$\mathrm{A}_{\mathrm{s}} \quad$ Surface area $\left(\mathrm{mm}^{2}\right)$

$\mathrm{Re} \quad$ Reynolds number

$\mathrm{V} \quad$ Average flow velocity $(\mathrm{m} / \mathrm{s})$

$\mathrm{K}_{\mathrm{f}} \quad$ Thermal conductivity of fluid (W/m K)

$\mu \quad$ Dynamic viscosity ( $\mathrm{kg} / \mathrm{ms}$ )

$\mathrm{T}_{\mathrm{f} 1} \quad$ Fluid temperature for bottom channel $(\mathrm{K})$

$\mathrm{T}_{\mathrm{f} 2} \quad$ Fluid temperature for top channel (K)

$\mathrm{V}_{1} \quad$ Fluid inlet velocity for bottom channel $(\mathrm{m} / \mathrm{s})$

$\mathrm{V}_{2} \quad$ Fluid inlet temperature for top channel $(\mathrm{m} / \mathrm{s})$

$\mathrm{x} \quad$ Distance from the channel inlet $(\mathrm{mm})$

Lch Channel length. (mm)

$\mathrm{Ac}_{1} \quad$ Area cross section of channel 1

$\mathrm{Ac}_{2} \quad$ Area cross section of channel 2

Greek Symbols:

$\Delta \quad$ Difference

$\rho \quad$ Mass density $\left(\mathrm{kg} / \mathrm{m}^{3}\right)$

Subscripts:

1 Bottom Channel.

2 Top Channel.

ch Channel.

ct Trapezoidal channel.

wet Wetted.

\section{REFERENCES}

Leela Vinodhal, V., and Rajan, K.S., 2014, "Computational Analyses of New Microchannel Heat Sink Configuration," Energy conversion and Management, 86, 595-604. http://dx.doi.org/10.1016/j.enconman.2014.06.038.

Leng, C., Wang, X.D., Huang, T.H., and Yan, W.M., 2015, "Optimization of Thermal Resistance and Bottom Wall Temperature Uniformity of Double Layer Microchannel Heat Sink," Energy Conversion and Management, 93, 141-150. http://dx.doi.org/10.1016/j.enconman.2015.01.004.

Brinda, R. Daniel, J.D., and Sumangala, K., 2012, "Ladder Shape Micro Channels Employed High Performance Cooling System for ULSI,” International Journal of Heat and Mass Transfer, 55, 3400-3411.

http://dx.doi.org/10.1016/j.ijheatmasstransfer.2012.03.044

Gunnasegaran, P., Mohammed, H.A., Shuaib, N.H., SaiDur, R., 2010, “The Effect of Geometrical Parameters on Heat Transfer Characteristics of Microchannels Heat Sink with Different Shape," International Communication of Heat and Mass Transfer, 37, 1078-1086.

http://dx.doi.org/10.1016/j.icheatmasstransfer.2010.06.014

Wei, X., Joshi, Y., and Patterson, M., 2007, "Experimental and Numerical Study of Stacked Microchannel Heat Sink for Liquid Cooling of Microelectronic Devices," Journal of Heat Transfer, 129(10), 1432-1444. http://dx.doi.org/10.1115/1.2754781.

Qu, W., Mala, G., M., and Li, D., 2000, "Heat Transfer for Water Flow in Trapezoidal Silicon Microchannels," International Journal Heat and Mass Transfer, 43, 3925-3936.

http://dx.doi.org/10.1016/S0017-9310(00)00045-4 